\title{
A formação profissional de Biblioteconomia para atuação em bibliotecas escolares: retrato das universidades federais brasileiras
}

\author{
Professional training of Librarianship for action in school libraries: brazilian federal \\ universities
}

\author{
Andrea Pereira Santos \\ Doutora em Geografia pela Universidade Federal de Goiás, Brasil. \\ Professora Adjunta do Curso de Biblioteconomia da Universidade Federal de Goiás, Brasil. \\ E-mail: andreabiblio@ufg.br \\ Vanessa Ferreira de Almeida Resende \\ Graduanda do curso de Biblioteconomia da Universidade Federal de Goiás, Brasil. \\ E-mail: vah.resende@gmail.com
}

\section{Resumo}

Trata-se de um estudo cujo objetivo é analisar os projetos pedagógicos dos cursos de Biblioteconomia das universidades federais brasileiras e responder a seguinte problemática: como acontece a formação de bibliotecários nas universidades para atuação em bibliotecas escolares? A justificativa para tal indagação é o crescimento das demandas do mercado de trabalho com o advento da Lei n. 12.244 de junho de 2010, que estabelece a universalização das bibliotecas em instituições de ensino e o prazo máximo de dez anos para que expirou em junho de 2020. A metodologia deste trabalho consiste em uma pesquisa exploratória, utilizando-se de métodos quantitativos para seu desenvolvimento. Além da fundamentação teórica que trará os conceitos base que norteiam esse trabalho. O estudo integrou algumas fases básicas da pesquisa: 1) busca no portal E-mec por cursos de biblioteconomia ofertados pelas universidades federais; 2 ) análise, a partir dos currículos, de conteúdos acerca da biblioteca escolar; 3) apresentação dos dados identificando os componentes curriculares com temáticas buscadas pela pesquisa e 4) tabulação do dados por regiões geográficas. Os resultados obtidos foram confrontados com o embasamento teórico, levando em consideração os conceitos de biblioteca escolar, letramento informacional, competência informacional e pesquisa escolar. Os resultados apresentam indícios no qual os cursos de Biblioteconomia das instituições analisadas tendem à formação básica para biblioteca em seus moldes tradicionais e gerais, mas buscam, mesmo que timidamente, acompanhar as mudanças que ocorreram ao longo dos anos em especial a atuação na biblioteca escolar.

Palavras-chave: Biblioteca escolar. Formação. Curso de Biblioteconomia. Universidades Federais.

\begin{abstract}
This is a study whose objective is to analyze the pedagogical projects of the Librarianship courses of the Brazilian federal universities and to answer the following problem: how does the training of librarians in universities to work in school libraries happen? The justification for such inquiry is the growth in the demands of the labor market with the advent of Law no. 12,244 of May 2010, which establishes the universalization of libraries in educational institutions and the maximum period of ten years that expired in June 2020. The methodology of this work consists of an exploratory research, using quantitative methods for its development. In addition to the theoretical foundation that will bring the basic concepts that guide this work. The study integrated some basic phases of the research: 1) searching the E-mec portal for library courses offered by federal universities; 2) analysis, from the curriculum, of content about the school library; 3) presentation of the data identifying the curricular components with themes sought by the research and 4) tabulation of the data by geographic regions. The results obtained were compared with the theoretical basis, taking into account the concepts of school library, information literacy, information competence and school research. The results show evidence that the courses in Librarianship at the institutions analyzed tend to basic education for the library in its traditional and general molds, but seek, even if timidly, to keep up with the changes that have occurred over the years, especially the performance in the school library.
\end{abstract}

Keywords: School library. Professional training. Librarianship. Brasilian federal university.

Bibl. Esc. em R., Ribeirão Preto, v. 7, n. 2, p. 82-101, 2021.

DOI: 10.11606/issn.2238-5894.berev.2021.173390 


\section{Introdução}

O cerne do trabalho dos profissionais formados em Biblioteconomia é o fazer social, sem o qual as demais atividades técnicas e os esforços não teriam sentido. Conhecer o acervo e os usuários é um dos deveres do profissional da informação atuantes nessas unidades, pois esse conjunto é que dá sentido à existência da biblioteca, ou seja, eles se complementam e tornam a biblioteca dinâmica e viva. Partindo desta afirmação, entende-se as bibliotecas escolares como tendo um papel fundamental na formação do estudante, por meio de todo seu potencial educativo e informacional, entregando ferramentas para a construção do conhecimento, pois é nela que eles têm o primeiro contato formal com a pesquisa.

A história da biblioteca escolar muitas vezes se confunde com a história da educação no Brasil, sendo o século XX um importante marco para sua estruturação e legitimação. Essa tipologia de biblioteca vem conquistando seu lugar através das reformas realizadas no sistema de ensino, as quais passaram por diversas mudanças ao longo do tempo. Apesar de não estar diretamente atrelada as reformas do sistema de ensino, em maio de 2010, houve a importante conquista que foi a promulgação da Lei n. 12.244 que dispõe sobre a universalização das bibliotecas nas instituições de ensino do país. Essa lei atende uma antiga reivindicação de bibliotecários e movimentos educacionais atentos para a importância de um olhar mais acurado para as bibliotecas escolares. Além disso, atualmente está tramitando o Projeto de Lei 9.484/18, propondo alterações no texto da lei original da lei 12.244.

Diante deste cenário, nosso objetivo geral é analisar os projetos pedagógicos dos cursos de Biblioteconomia das universidades federais brasileiras e responder a seguinte problemática: como acontece a formação de bibliotecários nas universidades para atuação em bibliotecas escolares? Para se responder a tal questionamento, delimitou-se como objetivos específicos: Realizar o levantamento dos projetos pedagógicos dos cursos de Biblioteconomia das universidades federais brasileiras e buscar a relação entre disciplinas que contextualizem a biblioteca escolar.

A pesquisa parte da hipótese, visando confirmar, que a formação realizada pelas universidades federais não é suficiente para atender as especificidades desta tipologia de biblioteca, impactando na formação dos profissionais para atuação em bibliotecas escolares.

O estudo se justifica pela atualização dos estudos realizados anteriormente; pela exigência da Lei n. 12.244/2010, a qual determina que escolas públicas e particulares possuam 
A formação profissional de Biblioteconomia para atuação em bibliotecas escolares: retrato das universidades federais brasileiras

uma biblioteca com acervo de pelo menos um livro para cada aluno matriculado e que essas bibliotecas tenham um profissional de biblioteconomia. Lembrando que o prazo máximo de aplicação da lei encerrou-se em maio do ano de 2020. Segundo o "Estudo Técnico da Consultoria Legislativa", até o ano de 2016, apenas 21\% das escolas públicas brasileiras possuíam bibliotecas em suas dependências; na rede privada de ensino, 38\% possuem esse equipamento escolar (CÂMARA DOS DEPUTADOS, 2017, p. 17). Entende-se que a biblioteca escolar apresenta uma demanda crescente por profissionais, tornando esse estudo importante para se ter uma visão global deste cenário.

Outra justificativa é entender como se dá a formação de profissionais para a atuação em bibliotecas escolares e a figura do Bibliotecário como mediador e ator do desenvolvimento informacional, uma vez que sabe-se da importância das bibliotecas escolares na formação escolar básica e na ampliação das habilidades informacionais dos estudantes em função de uma maior competência leitora e de pesquisa.

\section{Biblioteca escolar: aspectos teóricos e conceituais}

O entendimento da biblioteca como instrumento indispensável nas instituições de ensino é uma pauta relativamente recente na história da educação brasileira. Embora as primeiras escolas, em meados do século XVI sob a coordenação dos jesuítas, já contassem com bibliotecas, conforme explicita Moraes (2006, p. 7), podemos afirmar que um olhar voltado para a função das bibliotecas é relativamente atual.

Nesse sentido, a história da biblioteca escolar é mais recente ainda e entrelaça-se com a história da educação, marcada por vários acontecimentos, conforme foi levantado por Sala e Militão (2017). Os autores apontam como se deu a relação entre as bibliotecas e a educação, demonstrando que entre as décadas de 1930 até 1980 poucos avanços foram obtidos no que tange à biblioteca escolar. A partir da década de 1990 começam a existir políticas nacionais, de forma tímida, apresentando alguns parâmetros para o desenvolvimento da biblioteca escolar do país.

Deve-se destacar a Lei n. 9.394/1996, que Estabelece as "Diretrizes e Bases da Educação Nacional", assim como os "Parâmetros Curriculares Nacionais - PCN" (1997), que são documentos que contemplam a biblioteca escolar como um ambiente pedagógico, e também de incentivo à leitura, oferecendo assim um referencial capaz de auxiliar os professores no esforço

Bibl. Esc. em R., Ribeirão Preto, v. 7, n. 2, p. 82-101, 2021. 
"de fazer com que as crianças dominem conhecimentos necessários para crescerem como cidadãos plenamente reconhecidos e conscientes de seu papel em nossa sociedade" (BRASIL, 1997, v. 1, p. 5 apud SALA; MILITÃO, 2017).

Estes documentos denotam que para o exercício pleno da cidadania, exige-se que a escola forneça condições necessárias para o uso da linguagem, fundamentada na diversidade textual, reforçando a importância do uso da informação ao incluir como objetivo do ensino fundamental que o aluno "saiba utilizar diferentes fontes de informação e recursos tecnológicos para adquirir e construir conhecimentos" (BRASIL, 1997, v. 1, p. 108 apud SALA; MILITÃO, 2017).

Antes de prosseguir com o contexto histórico, é necessário compreender o conceito de biblioteca escolar e para isso deve-se considerar os seguintes documentos: o Manifesto IFLA ${ }^{1}$ /UNESCO ${ }^{2}$ para biblioteca escolar de 1999 e a $2^{\text {a }}$ edição das Diretrizes da IFLA para a biblioteca escolar de 2015.

O primeiro documento apresenta a missão da biblioteca escolar que é a de prestar "serviços de apoio à aprendizagem e livros aos membros da comunidade escolar, oferecendolhes a possibilidade de se tornarem pensadores críticos e efetivos usuários da informação, em todos os formatos e meios" (IFLA, 1999, p. 1). Este documento trata de aspectos relacionados ao quadro pessoal, fazendo um destaque para o bibliotecário responsável pela biblioteca, suas funções de serviço e gestão; tratando também do acervo da biblioteca, seu financiamento, principais objetivos e apresenta meios de que a biblioteca escolar deve dispor para atingir esses objetivos.

O segundo documento traz um conceito geral do que é uma biblioteca escolar:

\begin{abstract}
A biblioteca escolar é um espaço de aprendizagem físico e digital na escola onde a leitura, pesquisa, investigação, pensamento, imaginação e criatividade são fundamentais para o percurso dos alunos da informação ao conhecimento e para o seu crescimento pessoal, social e cultural. Este lugar físico e digital é designado por vários termos (por exemplo, centro de media, centro de documentação e informação, biblioteca/ centro de recursos, biblioteca/ centro de aprendizagem), mas biblioteca escolar é o termo mais utilizado e aplicado às instalações e funções (IFLA, 2015, p. 19).
\end{abstract}

\footnotetext{
${ }^{1}$ International Federation of Library Associations and Institutions (IFLA).

${ }^{2}$ Organização das Nações Unidas para a Educação, a Ciência e a Cultura (UNESCO).
} 
A formação profissional de Biblioteconomia para atuação em bibliotecas escolares: retrato das universidades federais brasileiras

Este mesmo documento traz o objetivo geral da biblioteca escolar: desenvolver nos estudantes a competência informacional, para que possam ser autônomos e conscientes de suas necessidades informacionais e sejam participantes responsáveis e éticos da sociedade (IFLA, 2015, p. 9).

A Competência em Informação é um processo pelo qual o indivíduo aprende a buscar, selecionar e avaliar as informações para tomada de decisões e produção de conhecimento. Ela dá suporte para a utilização de fontes de informação em seus suportes variados, tais como livros de referência e base de dados. Outro termo correlato é o Letramento informacional, que para alguns autores apresentam a mesma definição (VITORINO; PIANTOLA, 2009; CAMPELLO, 2009a; PAIVA; DUARTE; 2016; MONTEIRO, 2016).

Segundo Campello,

[...] podemos dizer que nos últimos anos tem havido grande disseminação do letramento informacional na biblioteconomia e na ciência da informação em vários países, abrangendo todos os continentes, concretizada em diversos tipos de iniciativas, envolvendo os mais diferentes contextos [...], refletindo o interesse da profissão em aprofundar sua função educativa. [...] No que diz respeito ao Brasil, a produção bibliográfica sobre letramento informacional encontra-se em estágio inicial. O termo e o conceito foram introduzidos no país por Caregnato, em 2000, e vêm sendo, desde então, trabalhados por diversos autores. Alguns utilizaram o termo no original: information literacy (DUDZIAK, 2003; BELLUZZO, 2001 e 2004); outros o traduziram por alfabetização informacional (CAREGNATO, 2000), competência informacional (CAMPELLO, 2003; LECARDELLI; PRADO, 2006; MELO; ARAÚJO, 2007; SILVA et al, 2005; FIALHO; MOURA, 2005;) e letramento informacional (CAMPELLO, 2003; GASQUE; TESCAROLO, 2007), tendo sido outros termos sugeridos por Dudziak (2003), tais como, fluência informacional e competência em informação. A maioria dos textos explora o conceito com base na literatura já existente sobre o tema, identificando vertentes e buscando entender sua origem, seu significado, sua importância e seu impacto na biblioteconomia/ciência da informação (CAMPELLO, 2009b, p.35).

A pesquisa escolar praticada pelo estudante, por sua vez, é o resultado da sua competência/letramento informacional, no qual ele poderá ser capaz de compreender e ser independente na sua busca por informações, conquistando assim seu cabedal informacional e, consequentemente, adquirindo conhecimento. Tal processo, evidentemente, mediado pelo professor e o bibliotecário (GIACUMUZZI, 2017), até que o estudante desenvolva habilidades e se torne independente informacionalmente.

Sendo assim, tendo como base a missão apresentada pelo "Manifesto IFLA/UNESCO para biblioteca escolar" (IFLA, 1999), fica evidente a necessidade de que o poder público, os professores, estudantes, bibliotecários e a sociedade percebam a importância da biblioteca escolar para o desenvolvimento social, com a finalidade de proporcionar a execução de políticas 
públicas efetivas e continuadas para que ela deixe de ser um sonho utópico e passe a fazer parte da realidade das escolas brasileiras.

Após a divulgação do Manifesto, houve no Brasil o desencadeamento de iniciativas as quais buscavam estabelecer práticas de incentivo à leitura, visando a promoção da biblioteca escolar como mediadora da informação com a sociedade. Dessa forma a principal política de incentivo e criação dessa tipologia de biblioteca foi instituída através da promulgação da Lei n. 12.244 de junho de 2010, competindo às instituições de ensino "desenvolver esforços progressivos" para o seu cumprimento (BRASIL, 2010).

Segundo Campello et al. (2012), a implementação da Lei n. 12.244/2010 foi resultado de esforços de bibliotecários, que já lutavam há muito tempo e vinham denunciando a inexistência de bibliotecas nas escolas e a debilidade das poucas existentes. A referida lei em seu Art. $1^{\circ}$ destaca que "As instituições de ensino públicas e privadas de todos os sistemas de ensino do País contarão com bibliotecas, nos termos desta Lei” (BRASIL, 2010). Em seu Art. $2^{\circ}$ define biblioteca escolar: "Para os fins desta Lei, considera-se biblioteca escolar a coleção de livros, materiais videográficos e documentos registrados em qualquer suporte destinados a consulta, pesquisa, estudo ou leitura" (BRASIL, 2010). A Lei estabelece ainda um prazo para sua efetivação, respeitando a profissão de bibliotecário e sua regulamentação.

Desde o ano de 2018, está em tramitação o Projeto de Lei 9.484 que propõe a alteração da Lei n. 12.244/2010. Dentre as principais alterações propostas, está modificar a definição de biblioteca escolar e a criação do Sistema Nacional de Bibliotecas Escolares (SNBE).

Segundo a redação final do Projeto, serão consideradas bibliotecas escolares:

[...]o equipamento cultural obrigatório e necessário ao desenvolvimento do processo educativo, cujos objetivos são:

I - Disponibilizar e democratizar a informação ao conhecimento e às novas tecnologias, em seus diversos suportes;

II - Promover as habilidades, as competências e as atitudes que contribuam para a garantia dos direitos e objetivos de aprendizagem e desenvolvimento dos alunos e alunas, em especial no campo da leitura e da escrita;

III - Constituir-se como espaço de recursos educativos indissociavelmente integrados ao processo de ensino-aprendizagem;

IV - Apresentar-se como espaço de estudo, de encontro e de lazer, destinado a servir de suporte para a comunidade em suas necessidades e anseios (BRASIL, 2019, p. 12).

Outro ponto importante a se destacar é a proposta de criação do Sistema Nacional de Bibliotecas Escolares - SNBE, que tem como suas principais funções incentivar a implementação de bibliotecas escolares no país, promovendo a melhoria do funcionamento 
A formação profissional de Biblioteconomia para atuação em bibliotecas escolares: retrato das universidades federais brasileiras

dessas instituições, definindo o acervo mínimo obrigatório para seu funcionamento, além de implementar uma política de acervos, proporcionando sua atualização de acordo com a legislação vigente e integrar através da rede de computadores todas essas bibliotecas. O sistema também desenvolverá atividades de treinamento e qualificação para os recursos humanos, além de estabelecer parâmetros funcionais para a instalação física, dando uma atenção maior à acessibilidade, tornando-a um espaço inclusivo.

Altera-se o prazo máximo para efetivação da Lei n. 12.244/2010, passando a vigorar o ano de 2024, para que seja efetivada no prazo máximo de vigência do Plano Nacional de Educação, aprovado pela Lei $n^{\circ} 13.005$, de 25 de junho de 2014. É indicado que ao menos 50\% (cinquenta por cento) de cada meta vinculada de universalização de bibliotecas escolares, nos termos estabelecidos pelo SNBE, deverão ser cumpridos até 2020 pelos sistemas de ensino.

No que toca em relação à profissão do bibliotecário nessas instituições, permanece, assim como na Lei n. 12.244/2010, às garantias prevista nas Leis $\mathrm{n}^{\circ} \mathrm{s} 4.084$, de 30 de junho de 1962, e 9.674, de 25 de junho de 1998.

\section{Os cursos de Biblioteconomia no Brasil e seus currículos}

Os cursos de Biblioteconomia no Brasil passaram por diversas fases desde sua implementação. O primeiro curso brasileiro nasce através do Decreto n. 8.835 de julho de 1911 (BRASIL, 1911) em que no artigo 34 é autorizada a criação de um Curso de Biblioteconomia no âmbito da Biblioteca Nacional, de caráter teórico e prático para a formação de pessoal. Suas aulas começam a ser ministradas em 1915. A formação realizada por esse curso, segundo Diorio (2015, p. 22) tinha uma característica mais humanística, diretamente influenciada pela École de Chartes. Mais tarde, em 1929, cria-se em São Paulo, no âmbito do Colégio Mackenzie, outro bacharelado com tendências mais tecnicistas, influenciado pelo modelo norte americano. $\mathrm{O}$ curso era ministrado para funcionários da biblioteca e de outras instituições do estado.

Diorio (2015, p. 23) explana que em 1936, o curso do Colégio Mackenzie encerra suas atividades e cria-se no Departamento de Cultura de São Paulo o curso de Biblioteconomia. Com o passar dos anos, surgiram outros cursos de Biblioteconomia pelo país, e não havia parâmetros que tratassem da criação dessas graduações, denotando uma grande variedade em relação às disciplinas ofertadas e sua carga horária, segundo o que demonstra o Parecer 460/82 (BRASIL, 1982).

Bibl. Esc. em R., Ribeirão Preto, v. 7, n. 2, p. 82-101, 2021. 
Com o advento da Lei n. 4.084/1962, a profissão de bibliotecário é regulamentada, garantindo o exercício profissional aos que possuem diploma de curso regular, sendo assim o primeiro currículo mínimo obrigatório para o curso de Biblioteconomia foi estabelecido pelo Conselho Federal de Educação, através da Resolução com data de 16/11/62, englobando as seguintes disciplinas: História do Livro e das Bibliotecas; História da Literatura; História da Arte; Introdução aos Estudos Históricos e Sociais; Evolução do Pensamento Filosófico e Científico; Organização e Administração de Bibliotecas; Catalogação e Classificação; Bibliografia e Referência; Documentação; e Paleografia.

Segundo o que explicita o parecer 460/82, até o ano de 1982 existia "trinta cursos de Biblioteconomia em nível de graduação, seis cursos de pós-graduação em nível de mestrado e um em nível de doutorado" (BRASIL, 1982). Houve diversas movimentações ao longo dos anos que buscavam a reestruturação do currículo mínimo do Curso de Biblioteconomia, aprovado em 1982, através do parecer 460/82 instituindo três disciplinas de fundamentação geral; quatro instrumentais; seis matérias de formação profissional, estipulando ainda o tempo mínimo de duração do curso de 2.500 horas/aula, que deveriam ser completos no prazo mínimo de quatro anos e máximo de sete anos.

Como dito anteriormente, muitas vezes a história da biblioteca escolar se entrelaça com a história da educação no Brasil. Desse modo, a criação do Programa Nacional Biblioteca da Escola, elaborado em 1997 através da portaria n. 584 de 28 de abril, que tinha como missão formar um acervo de bibliotecas escolares de referência para apoio pedagógico, com prazo máximo de execução de três anos, foi um dos marcos dessa história entrelaçada (BRASIL, 1997 apud SALA; MILITÃO, 2017).

No ano de 1997 entrou em vigor a Lei n 9.394 de 1996 (BRASIL, 1196), que estabelece as Diretrizes e Bases da Educação Nacional, prevendo o estabelecimento de novas Diretrizes Curriculares, dentre elas, fica estabelecido que o Projeto Pedagógico Curricular (PPC) seria responsabilidade das escolas de formação. Com isso, foi criada uma comissão que definiria bases para o currículo mínimo, concluída em 2001 apresentando o parecer 492/2001 (BRASIL, 2001), em que foram enumeradas as competências e habilidades necessárias ao profissional bibliotecário, sendo estas competências gerais e específicas. A partir daí ficou estabelecido que as escolas de Biblioteconomia definiriam a estrutura geral de seus projetos e os critérios para avaliação periódica de acordo com sua instituição de ensino ao qual o curso está inserido. 
A formação profissional de Biblioteconomia para atuação em bibliotecas escolares: retrato das universidades federais brasileiras

Com a promulgação da Lei n.12.244/2010 (BRASIL, 2010), ficou estabelecido que todas as escolas, deveriam possuir uma biblioteca com pelo menos um exemplar de livro por aluno, como explicitado anteriormente. Em julho de 2017, foi realizado um estudo técnico pela Consultoria Legislativa fazendo uma análise da aplicação da Lei. A conclusão foi que deverse-ia fazer uma revisão da mesma por conter diversas lacunas para sua aplicação abrindo brechas para que a Lei não fosse efetivamente aplicada (CÂMARA DOS DEPUTADOS, 2017).

Face a esses acontecimentos, entende-se a importância da inserção de conteúdos que tratem da biblioteca escolar nos currículos dos cursos de graduação em Biblioteconomia, o qual será detalhado na seção de resultados.

\section{Caminho metodológico}

Considerando a problemática tratada por este estudo - relacionada à formação de bibliotecários para atuar em bibliotecas escolares, realizadas pelas universidades federais brasileiras - a pesquisa assumiu uma abordagem quantitativa de natureza exploratória.

A abordagem quantitativa tem seus fundamentos no pensamento positivista, tendendo a enfatizar o raciocínio dedutivo, seguindo regras em que a lógica pode ser aplicada e seus atributos mensuráveis através da experiência humana (SILVEIRA; CÓRDOVA, 2009, p. 33). A pesquisa exploratória segundo Gil (2007 apud SILVEIRA; CÓRDOVA, 2009, p. 35), tem o objetivo de familiarizar o pesquisador com o problema, com escopo de torná-lo mais explícito ou possibilitando a criação de hipóteses. Os procedimentos utilizados foram a pesquisa bibliográfica e a documental, de modo a entender as investigações já realizadas acerca da temática abordada.

Com base nessas diretrizes, foram estabelecidas as seguintes etapas do planejamento:

a) busca das instituições de nível superior através do portal $e-m e c^{3}$;

b) mapeamento dos cursos de Biblioteconomia das universidades federais;

\footnotetext{
${ }^{3}$ Sistema criado em 2007, pelo Governo Federal, que permite a abertura e o acompanhamento dos processos pelas instituições de forma simplificada e transparente, podendo ser acessado pelo site: http://emec.mec.gov.br/. Acesso em 13 nov. 2019.
} 
c) levantamento, via site das instituições selecionadas, dos projetos pedagógicos dos cursos presenciais e à distância de Biblioteconomia;

d) busca da relação de disciplinas que abordem temáticas relacionadas as bibliotecas escolares;

e) Análise da ementa das disciplinas selecionadas ${ }^{4}$;

f) Tabulação dos dados obtidos na coleta;

g) Apresentação dos resultados da análise.

Os resultados obtidos por meio da análise dos dados foram analisados à luz da fundamentação teórica que embasa esta pesquisa, levando em consideração conceitos de biblioteca escolar, letramento informacional e/ou competência em informação ${ }^{5}$ e pesquisa escolar, bem como os dados apresentados anteriormente por Moro et al. (2015) em seu livro “Contextos Formativos e Operacionais das Bibliotecas Escolares e Públicas Brasileiras”, em que o primeiro capítulo é dedicado a uma breve análise das disciplinas dos cursos de biblioteconomia. Há também o estudo de Diorio (2015) intitulado "Um olhar sobre a formação do bibliotecário escolar" que trata dos currículos das universidades brasileiras que ofertam o curso de Biblioteconomia, para uma possível comparação guardando a natureza e as devidas proporções de cada estudo. Serviram como embasamento os estudos de Campello (2009a, 2009b, 2012) que tratam a relação da biblioteca escolar e o letramento informacional.

Os critérios para a análise foram objetivos, sendo consideradas disciplinas que carregam a nomenclatura "Biblioteca Escolar"; disciplinas que tratam em sua ementa sobre bibliotecas escolares; disciplinas que contenham em sua bibliografia básica ou complementar textos que referenciam bibliotecas escolares. Tendo em vista o que foi encontrado na análise dos dados, para complementação da busca, entende-se o letramento informacional, a competência em informação ${ }^{6}$ e pesquisa escolar são elementos indispensáveis para atuação desses profissionais nessas tipologias de bibliotecas. As demais disciplinas de núcleo comum, não foram

\footnotetext{
${ }^{4}$ Foi revisado título, a ementa, o conteúdo programático das disciplinas e a bibliografia obrigatória, quando disponível.

${ }^{5}$ A UNESCO sugere o termo Competência em Informação para o Brasil (HORTON JR, 2013, p.172).

${ }^{6}$ Ou Competência Informacional que é frequentemente encontrado em textos mais antigos e que por esse motivo foi utilizado como descritor para a busca e mantido nas citações diretas.
} 
A formação profissional de Biblioteconomia para atuação em bibliotecas escolares: retrato das universidades federais brasileiras

consideradas, pois infere-se que servirão como base para atuação em qualquer unidade de informação.

\section{Cursos de Biblioteconomia: formação de bibliotecários escolares}

Nas considerações iniciais deste estudo, fora apresentada a problemática que nortearia os parâmetros para a análise da formação profissional do bibliotecário para atuação em Bibliotecas Escolares à luz do embasamento teórico que foi exposto anteriormente. A pesquisa também buscou realizar uma análise comparativa com os estudos de Moro et al. (2015) e Diorio (2015), que trouxeram um panorama de como era a formação de bibliotecários para atuação em bibliotecas escolares no Brasil até o ano de 2015, guardando a natureza e as devidas proporções de cada trabalho.

\section{As universidades federais brasileiras na formação de bibliotecários escolares}

A formação do bibliotecário, de forma geral, pode ser dividida em duas fases: a graduação e a pós-graduação. Essa última podendo ser dividida em lato ou stricto sensu. O objetivo deste estudo é entender através do currículo dos cursos, como se dá a formação de bibliotecários na graduação para atuação em bibliotecas escolares. Para tanto, foi realizado o recorte das universidades federais brasileiras que ofertam o curso de Biblioteconomia, seja ele na modalidade presencial ou de ensino à distância $(\mathrm{EaD})$.

Segundo o portal e-mec até março de 2020, existem no Brasil 58 ofertas de cursos de Biblioteconomia, dos quais $25^{7}$ são ofertados por instituições públicas federais. Foram analisados 21 Projetos Pedagógicos Curriculares - PPC, referentes a $19^{8}$ instituições de ensino, em todas as regiões do país. Apenas três cursos não foram analisados ${ }^{9}$, pois no decorrer desta pesquisa seus PPCs estavam em fase de revisão, resultado esse que só seria relevante para as

\footnotetext{
${ }^{7}$ Três cursos EAD e 22 presenciais.

${ }^{8}$ Há mais PPCs do que instituições pois algumas delas ofertam a modalidade do curso em EaD. Apesar do curso na modalidade EaD ser um projeto nacional, as instituições participantes tem a opção de acrescentar conteúdos específicos nos componentes curriculares de ementa aberta. É aí que podem aproveitar e inserir conteúdos relacionados à biblioteca escolar.

${ }^{9}$ As instituições que não participaram desta análise foram: Universidade de Brasília (UnB); Universidade Federal Fluminense (UFF) e Universidade Federal da Bahia (UFBA).
} 
próximas turmas formadas, ou seja, para no mínimo em quatro anos. O levantamento dos projetos pedagógicos dos cursos de Biblioteconomia das universidades federais brasileiras, foi realizado na página das suas respectivas faculdades e podem ser encontradas facilmente através do portal $e$-mec.

Para este estudo optou-se por fazer um levantamento por região e a busca, nos projetos pedagógicos, pelos termos: biblioteca escolar, letramento informacional, competência em informação e pesquisa escolar. A escolha de expandir coleta de dados para os termos que extrapolam o conceito de "biblioteca escolar", dá-se pelo fato que eles estão relacionados diretamente a esta tipologia de biblioteca, podendo assim inferir que a temática tratada é essencial para a formação de bibliotecários escolares. Na Tabela 1, podemos ver o percentual de universidades por região, em que são ofertados Cursos de Biblioteconomia.

Tabela 1 - Percentual de cursos de graduação em Biblioteconomia por região nas universidades federais

\begin{tabular}{lcc}
\hline \multicolumn{1}{c}{ REGIÃO } & NÚMEROS REAIS & PERCENTUAL \\
\hline Centro-Oeste & 3 & $13,6 \%$ \\
Nordeste & 9 & $40,9 \%$ \\
Norte & 2 & $9,1 \%$ \\
Sudeste & 5 & $22,7 \%$ \\
Sul & 3 & $13,6 \%$ \\
\hline
\end{tabular}

Fonte: Dados da pesquisa, 2020

Conforme podemos observar no gráfico o Nordeste é a região que conta com o maior número de cursos de Biblioteconomia oferecidos por universidades federais, sendo oito ofertas; em segundo lugar está o Sudeste com quatro, posteriormente a região Sul com três e por último, empatadas as regiões Norte e Centro-Oeste com duas cada uma.

A análise dos PPCs se deu em duas etapas. A primeira etapa levou em consideração as disciplinas específicas que tratam diretamente a temática abordada por este trabalho, levando em consideração os termos já expostos anteriormente. Em seguida foi realizado o levantamento de disciplinas generalizadas as quais, em algum momento, na ementa ou sua bibliografia, tratavam sobre bibliotecas escolares e seus termos correlatos. Nas próximas seções serão apresentados mais detalhes. 
A formação profissional de Biblioteconomia para atuação em bibliotecas escolares: retrato das universidades federais brasileiras

\section{Disciplinas específicas}

Para as disciplinas que foram aqui classificadas como específicas, optou-se por levar em consideração sua nomenclatura, ementa e bibliografia. Sendo assim, foi entendido que as disciplinas que levavam o nome de biblioteca escolar; letramento informacional, competência informacional, ou pesquisa escolar foram consideradas dentro da temática buscada para esta pesquisa.

Neste recorte, 16 PPCs de 15 universidades, apresentaram, em seus currículos, disciplinas que se encaixam como específicas, totalizando 19 ofertas. Para melhor apresentação dos dados, os termos buscados serão expostos na Tabela 2, identificando em números reais a quantidade de disciplinas específicas ofertadas por região:

Tabela 2 - Disciplinas específicas ofertadas por região

\begin{tabular}{l|l|c}
\hline \multicolumn{1}{c}{ DISCIPLINAS } & REGIÃO & NÚMEROS REAIS \\
\hline \multirow{3}{*}{ Biblioteca Escolar } & Nordeste & 5 \\
\cline { 2 - 3 } & Sudeste & 1 \\
\cline { 2 - 3 } & Sul & 3 \\
\hline \multirow{3}{*}{ Competência Informacional } & Nordeste & 1 \\
\cline { 2 - 3 } & Norte & 1 \\
\cline { 2 - 3 } & Sudeste & 2 \\
\cline { 2 - 3 } & Sul & 1 \\
\hline Letramento Informacional & Nordeste & 2 \\
\hline \multirow{2}{*}{ Pesquisa Escolar } & Centro-Oeste & 2 \\
\cline { 2 - 3 } & Nordeste & 1 \\
\hline
\end{tabular}

Fonte: Dados da pesquisa, 2020

Pode-se verificar ainda, na Tabela 3, em consonância com a Tabela 2, o núcleo de oferta das disciplinas abordando os termos selecionados com os currículos das instituições.

Tabela 3 - Percentual de núcleo de oferta de disciplinas específicas

\begin{tabular}{lcc}
\hline \multicolumn{1}{c}{ DISCIPLINAS } & NÚCLEO DE OFERTA & NÚMEROS REAIS \\
\hline \multirow{2}{*}{ Biblioteca Escolar } & Énfase & 1 \\
& Obrigatória & 2 \\
Competência Informacional & Optativa & 6 \\
& Obrigatória & 4 \\
Letramento Informacional & Optativa & 1 \\
& Obrigatória & 1 \\
Pesquisa Escolar & Optativa & 1 \\
& Obrigatória & 2 \\
\hline
\end{tabular}

Fonte: Dados da pesquisa, 2020

Conforme apresentado na Tabela 3, se visto globalmente, os cursos ofertam, em equilíbrio, disciplinas específicas com o núcleo obrigatório e optativo, sendo apenas uma universidade que oferta como ênfase. É interessante observar que como a biblioteconomia 
possui atuação em outras unidades de informação e/ou outras tipologias de bibliotecas, ao tornar optativa a disciplina, dá ao estudante a possibilidade de escolher qual área ele pretende se aprofundar.

\section{Disciplinas gerais}

A próxima etapa do estudo levou em consideração a menção aos termos: biblioteca escolar, competência/letramento informacional e pesquisa escolar; suas ementas, conteúdo programático e na bibliografia das disciplinas gerais do currículo. Foi identificada a oferta de 28 disciplinas, distribuídas em 13 PPCs do total de 19 universidades analisadas. Para melhor compreensão destes dados, serão apresentados no Quadro 1, os termos de busca, a região, o nome das disciplinas e o núcleo de oferta desses componentes curriculares.

Quadro 1 - Disciplinas gerais que mencionam a Biblioteca Escolar ou termos correlatos

\begin{tabular}{|c|c|c|c|}
\hline TERMO & REGIÃO & DISCIPLINA & $\begin{array}{c}\text { Núcleo de } \\
\text { Oferta }\end{array}$ \\
\hline \multirow{23}{*}{$\begin{array}{l}\text { Biblioteca } \\
\text { Escolar }\end{array}$} & \multirow{9}{*}{ Centro-Oeste } & $\begin{array}{l}\text { História dos registros de informação e } \\
\text { transmissão cultural }\end{array}$ & Obrigatória \\
\hline & & Formação e desenvolvimento de acervos & Obrigatória \\
\hline & & Leitura e sociedade & Obrigatória \\
\hline & & Formação e desenvolvimento de acervos & Obrigatória \\
\hline & & Gestão de TI em bibliotecas & Obrigatória \\
\hline & & $\begin{array}{l}\text { Tópicos contemporâneos em informação } \\
\text { social, cultural e educacional I e II }\end{array}$ & Optativa \\
\hline & & $\begin{array}{l}\text { Tópicos contemporâneos em produção, } \\
\text { organização e representação do } \\
\text { conhecimento II }\end{array}$ & Optativa \\
\hline & & Formação e desenvolvimento de acervos & Obrigatória \\
\hline & & $\begin{array}{l}\text { Estágio supervisionado em biblioteconomia } \\
2\end{array}$ & Obrigatória \\
\hline & \multirow{4}{*}{ Nordeste } & Unidades de informação II & Obrigatória \\
\hline & & Introdução à Biblioteconomia & Obrigatória \\
\hline & & $\begin{array}{l}\text { Unidades de informação públicas, escolares } \\
\text { e especializadas }\end{array}$ & Obrigatória \\
\hline & & Biblioteca e sociedade & Optativa \\
\hline & \multirow{5}{*}{ Norte } & Leitura e biblioteca & Optativa \\
\hline & & Leitura e cultura & Obrigatória \\
\hline & & Discurso, História e Memória & Ênfase \\
\hline & & Serviços específicos de informação & Optativa \\
\hline & & $\begin{array}{l}\text { Tópicos em gestão de unidades de } \\
\text { informação A, B, C, D }\end{array}$ & Optativa \\
\hline & \multirow{4}{*}{ Sudeste } & $\begin{array}{l}\text { Uso de fontes de informação em áreas } \\
\text { específicas }\end{array}$ & Optativa \\
\hline & & $\begin{array}{l}\text { Fundamentos educacionais em } \\
\text { Biblioteconomia }\end{array}$ & Obrigatória \\
\hline & & Estágio em Biblioteconomia & Obrigatória \\
\hline & & Tópicos especiais em Biblioteconomia I & Optativa \\
\hline & Sul & Unidades de informação gerais & Optativa \\
\hline
\end{tabular}

Bibl. Esc. em R., Ribeirão Preto, v. 7, n. 2, p. 82-101, 2021. 
A formação profissional de Biblioteconomia para atuação em bibliotecas escolares: retrato das universidades federais brasileiras

\begin{tabular}{|c|c|l|c|}
\hline & & Leitura, biblioteca e inclusão social & Obrigatória \\
\hline $\begin{array}{c}\text { Competência } \\
\text { Informacional }\end{array}$ & Nordeste & Serviço de informação e referência & Obrigatória \\
\cline { 2 - 4 } $\begin{array}{c}\text { Letramento } \\
\text { Informacional }\end{array}$ & Sudeste & Estudo de usuários & Obrigatória \\
\hline
\end{tabular}

Fonte: Dados da pesquisa, 2020

Como demonstrado no quadro 1, há uma quantidade significativa de disciplinas as quais, apesar de não conter no título "biblioteca escolar" trazem em seus conteúdos alusão à temática objeto dessa pesquisa.

\section{Análise dos dados}

Os critérios para a realização desta análise foram objetivos, sendo consideradas disciplinas que carregam a nomenclatura "biblioteca escolar" ou um de seus termos correlatos: competência/letramento informacional e pesquisa escolar. Também foram consideradas disciplinas que tratam em sua ementa sobre os termos; ou disciplinas que contenham em sua bibliografia básica ou complementar textos que referenciam bibliotecas escolares. As demais disciplinas, de núcleo comum, não foram consideradas, pois infere-se que servirão como base para atuação em qualquer unidade de informação.

Por meio dos PPCs dos cursos de Biblioteconomia das universidades federais brasileiras, pode-se chegar à seguinte conclusão, conforme os dados mostrados nas seções acima: dentre as 19 instituições analisadas, 15 contavam em sua ementa com pelo menos uma disciplina que trate especificamente sobre bibliotecas escolares ou seus termos correlatos, sendo ofertadas como obrigatórias ou optativas (Tabelas 2 e 3). Há também um total de 13 universidades, das 19 analisadas, que ofertam em sua grade curricular 27 disciplinas que abordam em algum momento a biblioteca escolar (Quadro 1).

No estudo publicado por Moro et al. (2015) discutiu-se os resultados dos Seminários Regionais de Bibliotecas Escolares e Públicas, realizados entre 2014 e 2015 em todas as regiões do país, buscando coletar informações sobre os contextos operacionais e de formação dos bibliotecários. Nesse seminário, o painel "Instituições Formadoras do Bibliotecário Brasileiro", foi estruturado com a finalidade de identificar as disciplinas que discutem conteúdos relativos à estrutura e funcionamento de bibliotecas escolares e públicas, assim como os preceitos éticos que devem orientar o exercício profissional do bibliotecário. A pesquisa fora realizada através de entrevistas com professores das instituições analisadas e seus resultados indicam que os

Bibl. Esc. em R., Ribeirão Preto, v. 7, n. 2, p. 82-101, 2021. 
passos dados em relação à inserção de disciplinas com temáticas voltadas exclusivamente para bibliotecas escolares ainda são tímidos. Na maioria dos casos, encontrados em todas as regiões do país, a Biblioteca Escolar é tratada transversalmente juntamente com outras tipologias de bibliotecas.

O estudo realizado por Diorio (2015) teve como objetivo apresentar a importância da formação do profissional bibliotecário para atuação em Bibliotecas Escolares. Para isso, foram mapeadas as instituições de ensino superior brasileiras, levando em consideração apenas os cursos presenciais e ativos, buscando disciplinas que abordam a temática e a forma que estas estão incluídas nos currículos dos cursos. O resultado da análise desses dados mostrou que, na maioria das vezes, os conteúdos dessas disciplinas estão associados a discussões generalizadas, não abordando aspectos importantes da ação das bibliotecas escolares, tais como o apoio às pesquisas, o domínio dos instrumentos de busca e de informação, para que os usuários tenham autonomia para construir seus conhecimentos, assim como, o incentivo às atividades de leitura.

Partindo do que foi exposto, e levando em consideração as conclusões apontadas pelas pesquisas anteriores a essa, pode-se inferir que os cursos de Biblioteconomia analisados por este estudo conseguem atingir um nível mínimo de preparação para a atuação de profissionais nesta tipologia de biblioteca. Conforme os dados apresentados, as disciplinas dedicadas ao estudo da biblioteca escolar, demonstra a preocupação em formar profissionais da informação para atuação nessa tipologia de biblioteca, apresentando uma oferta variada entre disciplinas obrigatórias e optativas. Também é possível observar, que a biblioteca escolar é abordada transversalmente em diversas disciplinas de núcleo comum.

Através dos conceitos apresentados de Biblioteca Escolar e seus termos associados: competência em informação, letramento informacional e pesquisa escolar, é possível afirmar, baseado nas Tabelas e Quadros apresentados, que os currículos das universidades federais os quais ofertam o curso de Biblioteconomia estão procurando uma aproximação desta tipologia de biblioteca, principalmente quando comparado aos estudo anteriores, buscando assim dar uma noção geral dos serviços prestados, da formação de acervos e atendimento do usuário. Por se tratar de uma análise quantitativa, não nos atemos a apresentar qualitativamente o conteúdo ministrado e sua eficácia. Tal análise poderá ser realizada em outros estudos.

Retomando a importância da Lei n. 12.244/2010 e o projeto de Lei 9.484/18, em que fala-se da universalização das bibliotecas escolares e da criação do SNBE, chega-se à conclusão que a formação oferecida por essas universidades ainda tem um viés voltado para a atuação 
A formação profissional de Biblioteconomia para atuação em bibliotecas escolares: retrato das universidades federais brasileiras

genérica em bibliotecas, mas que ainda assim, se esforçam para garantir que os egressos tenham conhecimentos diversos para realizar adequadamente seu trabalho, pode-se observar isso na quantidade de disciplinas específicas voltadas a formação para atuação em bibliotecas escolares.

A Lei n. 12.244/2010 não exige que o profissional tenha formação especializada em biblioteca escolar, mas é importante ressaltar que cada tipologia de biblioteca tem suas especificidades e seu público, que uma formação generalizada não dá conta de todas as nuances. Para que esse profissional esteja mais capacitado, é necessário que busque opções de educação continuada, através de cursos de pós-graduação lato ou stricto sensu, atualizando-se constantemente para que consigam dar o aporte necessário para atuarem de forma mais plena e satisfatória ante o cenário atual ao qual se insere as bibliotecas escolares.

\section{Considerações finais}

Este estudo teve a finalidade de realizar um levantamento de cursos de Biblioteconomia das universidades federais e verificar disciplinas e conteúdos com foco na temática bibliotecas escolares. O cenário para a realização da pesquisa, levou em consideração o fim do prazo estabelecido para a criação e universalização das Bibliotecas Escolares por meio da Lei n. 12.244/2010 e a tentativa de atualizar os estudos apresentados anteriormente. Para tanto, buscou-se entender, por meio da análise dos projetos curriculares, como está a formação de bibliotecários para atuação em bibliotecas escolares.

Compreende-se que a pesquisa atingiu seu propósito, pois de acordo com os levantamentos realizados, entendeu-se que a formação acadêmica do bibliotecário, nas universidades públicas federais, se dá pela oferta de disciplinas específicas e gerais as quais abarcam, pelo menos minimamente, o trabalho a ser realizado nesta tipologia de biblioteca. Os dados coletados, mostram que a região Nordeste é a que mais oferece ofertas de formação específica na tipologia de biblioteca pesquisada, totalizando oito disciplinas e infere-se que isso se deve ao fato de que a região é a com maior quantidade de cursos. Em seguida têm-se a região Sul com quatro; Sudeste com três; Centro-Oeste com duas e o Norte com uma.

Segundo o Estudo Técnico da Consultoria Legislativa (CÂMARA DOS DEPUTADOS, 2017, p. 17), apresentando anteriormente, é possível que, nos próximos anos, haja um crescimento das demandas do mercado de trabalho por conta de legislação a qual estabelece a 
criação de Bibliotecas Escolares. Desse modo, a tendência, cada vez maior, é de os currículos dos cursos de graduação passem por análises e reformas para atender a essa demanda crescente.

Pode-se perceber, através da análise dos PPCs, que o bibliotecário tem recebido uma sólida formação generalizada, e que estão cada vez mais procurando uma aproximação das Bibliotecas Escolares, mas essa formação pode e deve ser complementada através de cursos de especialização na área para melhoria profissional e pessoal.

A pesquisa aqui realizada através de métodos quantitativos, abordou uma vertente de forma pragmática, mas não buscou esgotar-se, indicando assim que o estudo deve ser aprofundado buscando métodos qualitativos. Além disso, é necessário que se faça uma pesquisa em nível nacional, levando em consideração todos os cursos ativos de Biblioteconomia, e os currículos vigentes atualmente para verificar se os resultados obtidos nesta pesquisa, observando se é necessária uma revisão dos currículos dos cursos de graduação de Biblioteconomia para suprir as novas tendências do profissional da informação.

\section{Referências}

BRASIL. Decreto $\mathbf{n}^{\circ}$ 8.835, de 11 de julho de 1911. Aprova o regulamento da Bibliotheca Nacional. Rio de Janeiro, 1911. Disponível em: https://www2.camara.leg.br/legin/fed/decret/1910-1919/decreto-8835-11-julho-1911-502890publicacaooriginal-1-pe.html. Acesso em: 03 jan. 2020.

BRASIL. Lei $\mathbf{n}^{\mathbf{0}} \mathbf{4 . 0 8 4}$, de 30 de junho de 1962. Dispõe sôbre a profissão de bibliotecário e regula seu exercício. Brasília, 1962. Disponível em:

https://www.planalto.gov.br/ccivil_03/Leis/1950-1969/L4084.htm. Acesso em: 12 dez. 2019.

BRASIL. Lei $\mathbf{n}^{\circ}$ 9.394, de 20 de dezembro de 1996. Estabelece as diretrizes e bases da educação nacional. Brasília, 1996. Disponível em:

http://www.planalto.gov.br/ccivil_03/leis/19394.htm. Acesso em: 03 jan. 2020.

BRASIL. Lei no 9.674, de 25 de junho de 1998. Dispõe sobre o exercício da profissão de Bibliotecário e determina outras providências. Brasília, 1998. Disponível em: http://www.planalto.gov.br/ccivil_03/Leis/L9674.htm. Acesso em: 12 dez. 2019.

BRASIL. Lei $\mathbf{n}^{0} \mathbf{1 2 . 2 4 4}$, de 24 de maio de 2010. Dispõe sobre a universalização das bibliotecas nas instituições de ensino do País. Brasília, 2010. Disponível em: http://www.planalto.gov.br/ccivil_03/_ato2007-2010/2010/lei/112244.htm. Acesso em: 30 nov. 2019.

BRASIL. Lei no 13.005, de 25 de junho de 2014. Aprova o Plano Nacional de Educação PNE e dá outras providências. Brasília, 2014. Disponível em: 
A formação profissional de Biblioteconomia para atuação em bibliotecas escolares: retrato das universidades federais brasileiras

http://www.planalto.gov.br/ccivil_03/_ato2011-2014/2014/lei/113005.htm. Acesso em: 12 dez. 2019.

BRASIL. Comissão de Constituição e Justiça e de Cidadania. Projeto de Lei no 9.484-C de 2018. Altera a Lei $n^{\circ} 12.244$, de 24 de maio de 2010, para modificar a definição de biblioteca escolar e criar o Sistema Nacional de Bibliotecas Escolares (SNBE). Brasília: Câmara dos Deputados, 03 out. 2019. Disponível em:

https://www.camara.leg.br/proposicoesWeb/prop_mostrarintegra;jsessionid=080527B66C0F0 DCBDC18ECB5B9DEF817.proposicoesWebExterno2? codteor $=1817567 \&$ filename $=$ Tramita cao-PL+9484/2018. Acesso em: 12 dez. 2019.

CÂMARA DOS DEPUTADOS (Brasil). Consultoria Legislativa. Bibliotecas escolares no Brasil: uma análise da aplicação da Lei no 12.244/2010. Estudo Técnico, Julho de 2017. Brasília, 2017.

CAMPELLO, Bernadete Santos. Letramento informacional: função educativa do bibliotecário na escola. Belo Horizonte: Autêntica, 2009a.

CAMPELLO, Bernadete Santos. Letramento Informacional no Brasil: práticas educativas de Bibliotecários em escolas de ensino básico. 2009. 208 f. Tese (Doutorado em Ciências da Informação) - Escola de Ciência da Informação, Universidade Federal de Minas Gerais, Belo Horizonte, 2009b.

CAMPELLO, Bernadete Santos et al. Situação das bibliotecas escolares no Brasil: o que sabemos? Biblioteca Escolar em Revista, Ribeirão Preto, v. 1, n. 1, p. 1-29, 2012.

Disponível em: http://www.revistas.usp.br/berev/article/view/106555/105152. Acesso em: 25 nov. 2019.

DIORIO, Marieli Sader. Um olhar sobre a formação do bibliotecário escolar. Orientador: Elisabete Gonçalves de Souza. 2015. 49 f. Trabalho de Conclusão de Curso (Bacharel em Biblioteconomia e Documentação) - Departamento de Ciência da Informação da Universidade Federal Fluminense, Niterói, 2015. Disponível em:

https://app.uff.br/riuff/bitstream/1/2666/1/DIORIO\%2C\%20Marieli.pdf. Acesso em: 01 out. 2019.

GIACUMUZZI, Gabriela da Silva. A competência informacional na pesquisa escolar da disciplina de Ciências. 2017. 49 f. Dissertação (Mestrado em Educação em Ciências) Instituto de Ciências Básicas em Saúde, Universidade Federal do Rio Grande do Sul, Porto Alegre, 2017.

HORTON JR, F. W. Overview of information literacy resources worldwide. Paris: UNESCO, 2013. http://unesdoc.unesco.org/images/0021/002196/219667e.pdf. Acesso em 9 fev. 2021.

IFLA. International Federation of Library Associations and Institutions. Manifesto da Biblioteca escolar da IFLA/UNESCO. 1999. Disponível em: https://archive.ifla.org/VII/s11/pubs/portuguese-brazil.pdf. Acesso em: 25 nov. 2019.

IFLA. International Federation of Library Associations and Institutions. Diretrizes da IFLA para biblioteca escolar. 2. ed. 2015. Disponível em: https://www.ifla.org/files/assets/school- 
libraries-resource-centers/publications/ifla-school-library-guidelines-pt.pdf. Acesso em: 25 nov. 2019.

BRASIL. Ministério da Educação. Conselho Federal de Educação. Currículo mínimo do curso de Biblioteconomia. Parecer no 460/1982. Brasília, 1 set. 1982. Disponível em:

http://www.dominiopublico.gov.br/download/texto/cd010161.pdf. Acesso em: 03 jan. 2020.

BRASIL. Ministério da Educação. Conselho Nacional de Educação. Diretrizes Curriculares Nacionais dos cursos de Filosofia, História, Geografia, Serviço Social, Comunicação Social, Ciências Sociais, Letras, Biblioteconomia, Arquivologia e Museologia. Parecer no 492/2001. Brasília, 3 abr. 2001. Disponível em: http://portal.mec.gov.br/cne/arquivos/pdf/CES0492.pdf. Acesso em: 03 jan. 2020.

MONTEIRO, Gisele Camargo. Competência em informação e biblioteca escolar. In: MONTEIRO, Gisele Camargo. A biblioteca escolar na formação de competências em informação: contribuições e perspectivas em bibliotecas do Colégio Pedro II. Orientador: Gilda Olinto. 2016. Dissertação (Mestrado em Ciências da Informação) - Escola de Comunicação, Universidade Federal do Rio de Janeiro, Rio de Janeiro, 2016. p. 29-33.

MORAES, Rubens Borba de. Livros e bibliotecas no Brasil colonial. 2. ed. Brasília: Briquet de Lemos, 2006.

MORO, Eliane Lourdes da Silva et al. Contextos formativos e operacionais das Bibliotecas Escolares e Públicas brasileiras. In: MORO, Eliane Lourdes da Silva et al. Contextos formativos e operacionais das bibliotecas escolares e públicas brasileiras. Brasília: Conselho Federal de Biblioteconomia, 2015. cap. 1, p. 20-43.

PAIVA, Marília de Abreu Martins de; DUARTE, Adriana Bogliolo Sirihal. Biblioteca Escolar: o que é?. Educação em Foco, Juiz de Fora, ano 19, n. 29, p. 87-106, set./dez. 2016.

SALA, Fabiana; MILITÃO, Silvio César Nunes. Biblioteca escolar no Brasil: origem e legislação nacional educacional. In: CONGRESSO NACIONAL DE EDUCAÇÃO (EDUCERE), 13., 2017, Curitiba. Anais [...]. Curitiba: [s. n.], 2017. Tema: História da Educação, p. 4669-4685. Disponível em: https://educere.bruc.com.br/arquivo/pdf2017/24341_12048.pdf. Acesso em: 18 dez. 2019.

SILVEIRA, Denise Tolfo; CÓRDOVA, Fernanda Peixoto. A pesquisa científica. In: UAB/UFRGS. Universidade Aberta do Brasil. Métodos de pesquisa. Porto Alegre: Ed. da UFRGS, 2009. cap. 2, p. 31-42. Disponível em: http://www.ufrgs.br/cursopgdr/downloadsSerie/derad005.pdf. Acesso em: 30 nov. 2019.

VITORINO, Elizete Vieira, PIANTOLA, Daniela. Competência informacional: bases históricas conceituais: construindo significados. Ciência da Informação, Brasília, v. 38, n. 3, p. 130-141, set./dez., 2009. Disponível em: http://www.scielo.br/pdf/ci/v38n3/v38n3a09.pdf. Acesso em: 27 nov. 2019. 